\title{
International Comparisons of Sports participation in European Countries: an Update of the COMPASS Project
}

\author{
Chris Gratton ${ }^{1}$, Nick Rowe ${ }^{2}$ and A. J. Veal ${ }^{3}$ \\ ${ }^{1}$ Sheffield Hallam University, UK \\ ${ }^{2}$ Strategic Lead for Research and Evaluation, Sport England, UK \\ ${ }^{3}$ University of Technology Sydney, Australia
}

\begin{abstract}
This paper looks back to an international comparative study of sports participation in seven European countries that was carried out in the late 1990s, COMPASS 1999. The original COMPASS study used data from the 1995-1997 period. This paper reviews the COMPASS framework and results, considers what new evidence is available to update the original COMPASS results, and considers what changes would be needed to the COMPASS approach if a new comparative study were undertaken today. Finally, the paper attempts to find explanations for the European pattern of sports participation revealed.
\end{abstract}

Keywords: COMPASS, international comparisons, sports participation

\section{Introduction}

COMPASS (Coordinated Monitoring of Participation in Sports) was a jointly funded initiative of the UK Sports Council, English Sports Council, and the Italian Olympic Committee (CONI), the aim of which was to examine existing systems for the collection and analysis of sports participation data in European countries with a view to identifying ways in which harmonisation may be achieved, so that greater comparability of data from different European countries would become possible. The COMPASS report (UK Sport, Sport England and CONI, 1999) was published in 1999 and provided comparative data on sports participation for seven European countries, Finland, Sweden, the Netherlands, UK, Ireland, Italy and Spain. The comparisons were made using an analytical framework that categorised participation into seven participation groups related to intensity of participation, club membership and whether participation was competitive or not. Despite the difficulties in making cross-national comparisons in sports participation across European countries, the COMPASS report has shown that there is evidence of an emerging European profile of sports participation. This paper attempts to build on the original COMPASS results and analyse what lessons can be learned for making comparisons of sports participation across European countries today.

The difficulties in comparing sports participation data collected in different countries have long been recognised, as have the potential benefits to sports administrators and decision makers in having access to comparable statistics. Various pieces of re- 
search have contributed towards our understanding of the difficulties associated with such comparisons.

\section{History}

Rodgers (1977) made the first attempt to make cross-national comparisons of sports participation in European countries. Rodgers attempted to compare the level of sports participation across seven European countries: Flemish Belgium, West Germany, the United Kingdom, the Netherlands, France, Norway and Spain. At the time, only one source of sports participation data was available for research purposes in each country and this varied from data collected in 1967 for the UK and France, to data collected in 1975 for Flemish Belgium. For the other three countries the survey year was 1974 . There is now evidence to suggest that there were considerable changes in the level of sports participation over the late 1960s and early 1970s so this diversity in the year of data collection was a considerable problem for comparative purposes. However, as Rodgers freely admitted, no two of these surveys were technically similar in questionnaire design, sample size, age of respondents, and the sports included, and therefore any cross-national comparisons of the general level of sports participation could not validly be made.

Despite these difficulties, Rodgers devised measures which allowed a crossnational comparison of the structures of sports participation in the various countries (i.e. the variation in sports participation with age, sex, education, and social groups) and his study showed substantial similarities in the pattern of sports participation between different European countries. In particular, he found a decline in sports participation with age in most countries, but less pronounced in Norway than in other countries. Also, in every country, men participated to a greater degree than women, and the drop-off after the age of 30 was much more pronounced in women than in men. Rodgers created the concept of 'sports literacy', the extent to which different groups had ever been exposed to sport, to explain these results. He argued that many women aged over 30, and men in older age groups, had not dropped out of sport but had never been involved in sport even when they were younger: that is, they were 'sports illiterate'.

In many ways the Rodgers study was way ahead of its time since, in the mid1970s, most European countries were collecting data on sports participation for the first time, and policy makers were more interested in discovering participation patterns in their own countries than making comparisons with others.

Following on from the Rodgers cross-comparative study, Kamphorst and Roberts (1989) attempted to make comparisons of sports participation across 15 different countries, which included Canada, India, Japan, New Zealand, Nigeria, and the USA as well as eight European countries. Cushman, Veal and Zuzanek (1996) attempted a similar exercise for all leisure activities, not just sport. Details of leisure participation for twelve countries were presented, five of which were European (France, Germany, Great Britain, Poland, and Spain).

All of these studies emphasise the theoretical and methodological problems that arise in attempting to make cross-national comparisons. However, despite the prob- 
lems, all these studies have succeeded in broadening and deepening our knowledge of sports participation across Europe, and the rest of the world.

In Europe, these studies revealed certain common patterns of participation and trends in participation. They concluded that there was a rapid growth in sports participation across most European countries in the 1960s and 1970s but that this slowed down in the 1980s. They also established that the pattern of decline in sports participation with age, and the relationship of sports participation and gender, with men participating more than women, was prevalent in virtually all European countries. Thus there is evidence of common patterns in European sports participation even though differences from one country to another prevail.

\section{The COMPASS Project}

COMPASS was different to the studies referred to above in that the objectives of the project were broader than simply to make cross-national comparisons of sports participation in European countries. In addition, the project aimed to promote harmonisation of sports participation statistics in Europe by persuading countries to adopt some aspects of a common methodology in the collection of survey data. That is, the long-term aim of COMPASS was to improve cross-national comparisons by reducing or eliminating the problems identified by it and earlier studies.

In the sports statistics field, there were several developments in the 1990s that laid the foundations for the COMPASS project. In August 1993, the first meeting was held of the Sports Statistics Committee of the International Statistical Institute. At that meeting participants agreed to work to improve the quality of national sports statistics and to develop a suitable methodology to enhance international comparisons. Further meetings of this committee took place in Beijing in 1995, and Istanbul in 1997.

In October 1995 a meeting of the Sports Research Officers Network (SRONET) of the Council of Europe's Committee for the Development of Sport (CDDS) took place in the UK. At that meeting a proposal was made by the former Great Britain Sports Council, and independently by the Italian Olympic Committee (CONI), to undertake a research project to investigate the availability of sports participation survey data in Europe, and to attempt to make cross-national comparisons where appropriate. The objective was to identify problems in making such comparisons with a long-term aim of moving towards greater harmonisation and comparability of sports participation data across European countries.

Following on from the widespread support for the project demonstrated at the SRONET meeting, the joint Anglo-Italian COMPASS project was initiated as an official initiative of the CDDS, jointly led by the United Kingdom and Italy.

\section{Definition of Participation in Sport}

The starting point for the definition of sport for the COMPASS project was the Council of Europe's European Sports Charter which adopted the following definition: 
Sport means all forms of physical activity which, through casual or organised participation, aim at expressing or improving physical fitness and mental wellbeing, forming social relationships or obtaining results in competition at all levels. (Council of Europe, 1992)

This broad definition of sports participation, however, needs to be operationalised for the purposes of making cross-national comparisons of sports participation. European countries that adopt the European Sports Charter do not necessarily adopt the above definition when they come to collect survey data on sports participation. The definition does not specify such matters as the reference period over which participation is recorded, the frequency level which determines 'participation' or the lower or upper ageranges of people to be included. Furthermore, the definition does not make clear whether all the criteria included in the definition must be satisfied for an activity to be classified as sport, so different countries arrive at different lists of activities that they consider to be sport.

A key question to be answered is how to distinguish between active sport and more general leisure and recreation activities. Certain activities fall easily into one category or the other. Football, tennis, and basketball are clearly sports and will be recognised by every country as active sports. Going to the cinema, going out for a meal, or watching television are other activities done in leisure time that are clearly non-sport. It is at the margin that the problem arises. Are darts and snooker, for example, sporting activities or leisure activities?

It could be argued that they are sports since television coverage of such activities occurs in sports programmes, and newspaper coverage is in the sports section. These activities are also competitive, with world championships in both, but they involve relatively little physical exertion. In countries where these activities are popular (e.g. the UK), they are normally included as sports in sports participation surveys. The problem is that this considerably increases the overall level of sports participation in those countries compared with countries where they are minor activities.

Another set of activities, that are physical activities but not competitive, are also often included in national sports participation surveys. Activities such as gardening are physical but generally regarded as non-sport, although this activity is included in some participation surveys, normally when the survey is of 'sports and physical activities' rather than just sports. More problematical in this category of activities is walking. Although many types of walking, such as strenuous walking in mountains and the countryside, are clearly active recreation giving the same sort of health benefits as sport, other types of walking, such as walking to the shops or walking to work, are less clearly defined as sport. This presents a serious problem in interpreting the category 'walking' when it arises in participation surveys. Normally, it will represent a wide range of types of activity, some of which we would not want to include as sport. It is an activity that is particularly problematical for international comparisons since it tends to have a very high participation rate in northern European countries and a relatively low rate in central and southern European countries. 
The situation is shown simply in Figure 1. The inner circle represents activities that are accepted as sport in all countries. The difference between this inner circle and the second circle represents activities such as those discussed above that form a 'grey area'. This may vary from country to country. The white outer area represents activities that are clearly regarded as non-sport in all countries.

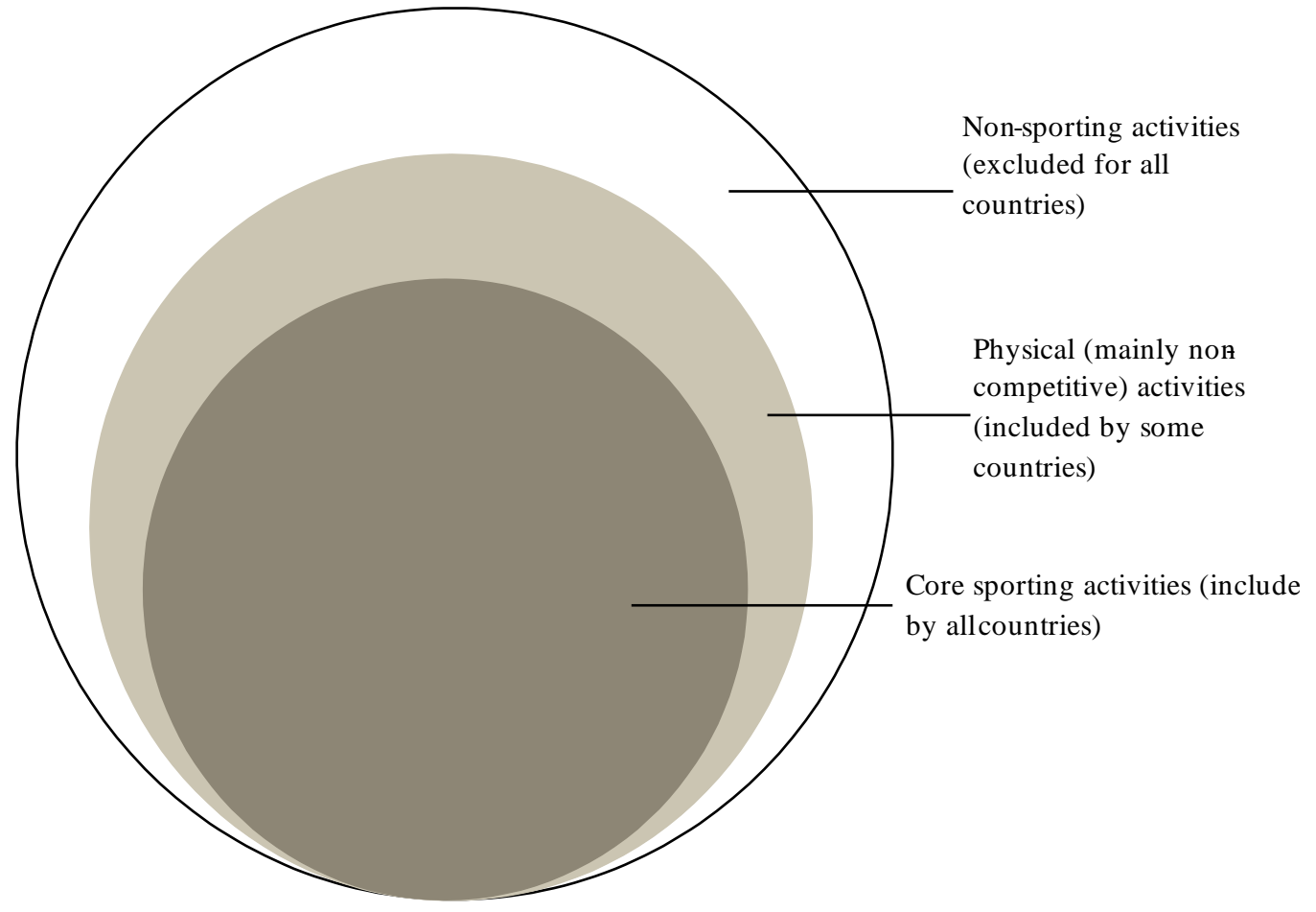

Figure 1. Conceptual Classification of Leisure Time Activities

From the practical point of view, it is activities in the 'grey area' that present problems for cross-national comparisons. Since COMPASS was dealing with survey data that had already been collected, a pragmatic decision was taken to treat those that participated only in 'grey area' activities, and not in any core activities, as non-participants in sport. That is, those people who only took part in walking, and no other activity would be classified as a non-participant for the purposes of COMPASS. A similar decision was taken for darts, snooker, gardening, and games such as chess and cards. Activities such as keep-fit, yoga and aerobics, on the other hand, which are non-competitive, are included in sports participation since they tend to be regarded as active sport in all countries and therefore would be part of the core sporting activities.

Thus COMPASS was compelled to adopt an approach to exclude from its definition some of the activities that many countries included in their sports participation surveys in order to make comparisons with other countries that do not include such activities.

\section{The COMPASS Analytical Framework}

The analytical framework adopted in COMPASS was based on analysing the structure of sports participation across a spectrum ranging from no participation at all to high 
intensity, frequent participation at a competitive level, and being a member of a sports club. It therefore comprised quantitative and qualitative components which were used to divide participation into seven groups, as shown in Table 1.

Table 1: COMPASS Analytical Framework and Activity Group Characteristics

\begin{tabular}{lccc}
\hline Groups & $\begin{array}{c}\text { Frequency per } \\
\text { annum }\end{array}$ & Club member & Competitive \\
\hline 1. Competitive, organised intensive & $\exists 120$ & $\checkmark$ & $\checkmark$ \\
\hline \multirow{2}{*}{ 2. Intensive } & $\exists 120$ & $\mathrm{x}$ & $\mathrm{x}$ \\
& $\exists 120$ & $\mathrm{X}$ & $\checkmark$ \\
\hline 3. Regular, competitive and/or organised & $\exists 120$ & $\mathrm{x}$ & $\checkmark$ \\
& $60-119$ & $\checkmark$ & $\mathrm{x}$ \\
\hline 4. Regular, recreational & $60-119$ & $\mathrm{X}$ & $\mathrm{x}$ \\
\hline 5. Irregular & $60-119$ & $\checkmark$ & $\checkmark$ \\
& $60-119$ & $\checkmark$ & $\mathrm{x}$ \\
& $12-59$ & $\mathrm{x}$ & $\checkmark$ \\
\hline 6. Occasional & $12-59$ & $\mathrm{x}$ & $\mathrm{x}$ \\
& $12-59$ & $\checkmark$ & $\mathrm{x}$ \\
& $12-59$ & $1-11$ & $\checkmark$ \\
\hline 7. Non-participant & $1-11$ & $\mathrm{x}$ & $\mathrm{x}$ \\
\hline
\end{tabular}

The quantitative component of participation is measured by the frequency of participation over the year prior to interview, varying from 'Intensive' (120 occasions or more) to 'Non-participant' (zero occasions). In-between these two extremes there are three categories: 'Regular' (60 to 119 occasions); 'Irregular' category (12-59 occasions); and 'Occasional' (1-11 occasions). The qualitative components refer to whether participation was competitive or not and whether any occasion of participation was as a member of a sports club. These components were only used in the 'Intensive' and 'Regular' groups as these two components are less relevant for the 'Irregular' and 'Occasional' groups. The result is the seven groups shown in Table 1.

\section{Results: COMPASS 1999}

This section concentrates on the main results from the COMPASS 1999 study. Table 2 compares sports participation across the seven countries for adults aged 16 and over (19 and over in Finland), using the analytical framework described above. The table indicates that there is a remarkable degree of variation in overall participation rates with Finland having only $19 \%$ of the adult population in the 'Non-participant' group compared with Italy with $77 \%$ and Spain with $69 \%$.

The UK, Ireland, and the Netherlands are similar in both the overall level of participation and the structure of participation over the various groups. Sweden and Finland stand out as having both the highest levels of participation and remarkably high levels in the two intensive groups. 39\% of adults in Finland and 36\% in Sweden are in either the 'Competitive, organised, and intensive' group or the 'Intensive' group, 
though in both cases most of these are in the latter group. In comparison, only $18 \%$ are in these two groups in Ireland, 16\% in the Netherlands, and 18\% in the UK.

Table 2: Sports participation in seven European countries (1990s, adults 16+*)

\begin{tabular}{lccccccc}
\hline Groups (see Table 1) & Spain & $\begin{array}{c}\text { Fin- } \\
\text { land }\end{array}$ & Ireland & Italy & $\begin{array}{c}\text { Nether- } \\
\text { lands }\end{array}$ & Sweden & UK \\
\hline 1 Competitive, organised, intensive & 2 & 6 & 7 & 2 & 8 & 12 & 5 \\
\hline 2 Intensive & 7 & 33 & 11 & 3 & 8 & 24 & 13 \\
\hline 3 Regular, competitive and/or organised & 2 & 5 & 7 & 2 & 10 & 5 & 4 \\
\hline 4 Regular, recreational & 4 & 28 & 3 & 3 & 6 & 17 & 6 \\
\hline 5 Irregular & 10 & 6 & 15 & 8 & 25 & 11 & 19 \\
\hline 6 Occasional & 6 & 2 & 21 & 5 & 6 & N/A & 20 \\
\hline 7 Non-participant & 69 & 19 & 36 & 77 & 37 & 30 & 34 \\
\hline
\end{tabular}

* Except Finland, 19+

There appears to be a north/south pattern in the structure of sports participation in Europe: Nordic countries seem to have both the highest levels of sports participation and take part, on average, more frequently than countries to the south of them. Also, there appears to be a further fall in both participation and intensity as we move further south to the Mediterranean countries.

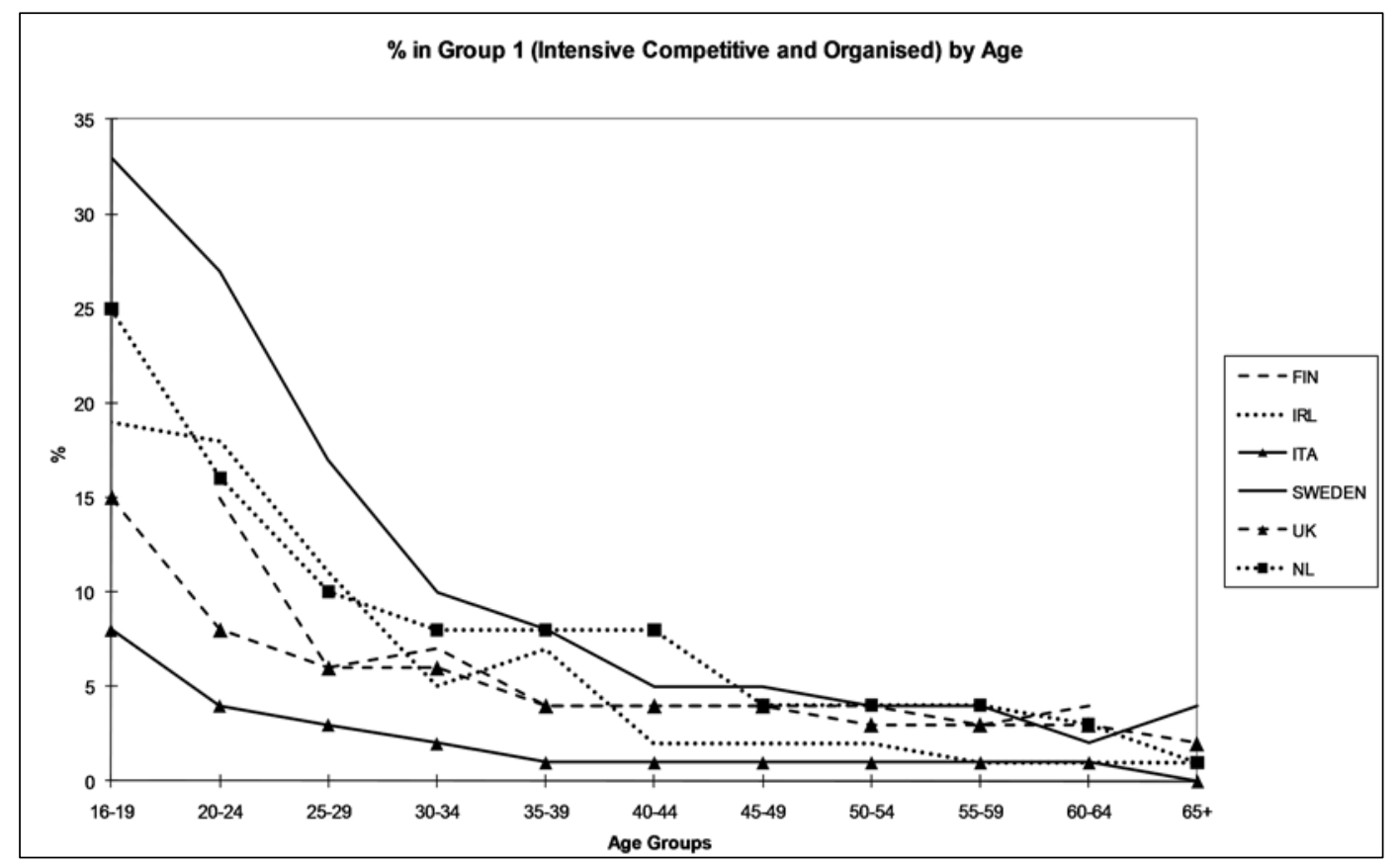

Figure 2: Group 1 (Intensive Competitive and Organised) by Age

Figures 2 and 3 highlight the essential differences for the Nordic countries in the study and the rest. Figure 2 shows the relationship between participation in group 1, competitive, intensive and organised, and age. The pattern of rapid decline with age is the same across all countries in this group. Although there are considerable differences 
between countries for the younger age groups, by the age of 40 these differences have mainly disappeared. Breaking the data down into males and females also shows that for all countries males dominate females in this group.

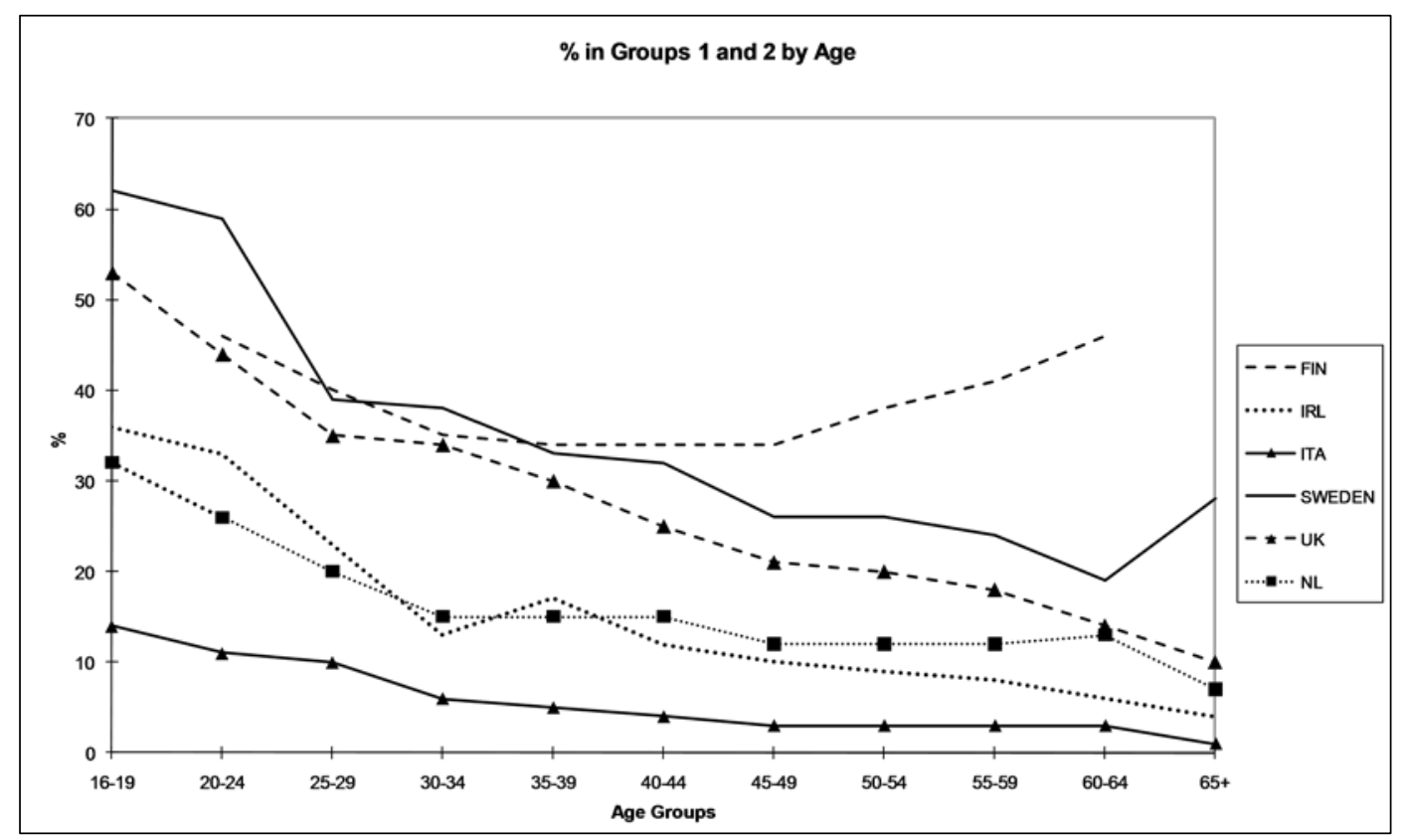

Figure 3: Groups 1 and 2 by Age

Figure 3 combines groups 1 and 2 and looks at all participants that take part at least 120 times a year, irrespective of whether it is competitive and/or organised. The figure shows much more diversity between countries. Here we find two countries, Finland and Sweden, have a very different pattern to the others with a very small decline with age and increases in participation for the oldest age group. Breaking down the data by gender also shows that women's participation is greater than men's when we combine these two groups in these two countries which is not the case in any of the other countries, where male participation is always higher than females for this intensive group of participants.

Figure 4 emphasises this pattern by looking at groups 6 and 7, occasional and nonparticipation, in relation to age. Finland stands out as having the smallest percentage of the population in these two groups and, after the age of 25, there is no substantial increase in the percentage doing little or no sport. Sweden has some increase in these groups with age but again a decline in the oldest age group is in contrast to all other countries.

The main result then of the COMPASS 1999 project was to identify the Nordic countries, as represented by Finland and Sweden in the study, as having much higher levels of regular sports participation than other European countries. Not only were their participation rates higher than other countries but there was less decline with age and no significant difference between the participation of men and women in contrast to all other countries in the study where male participation was higher than female participation. 


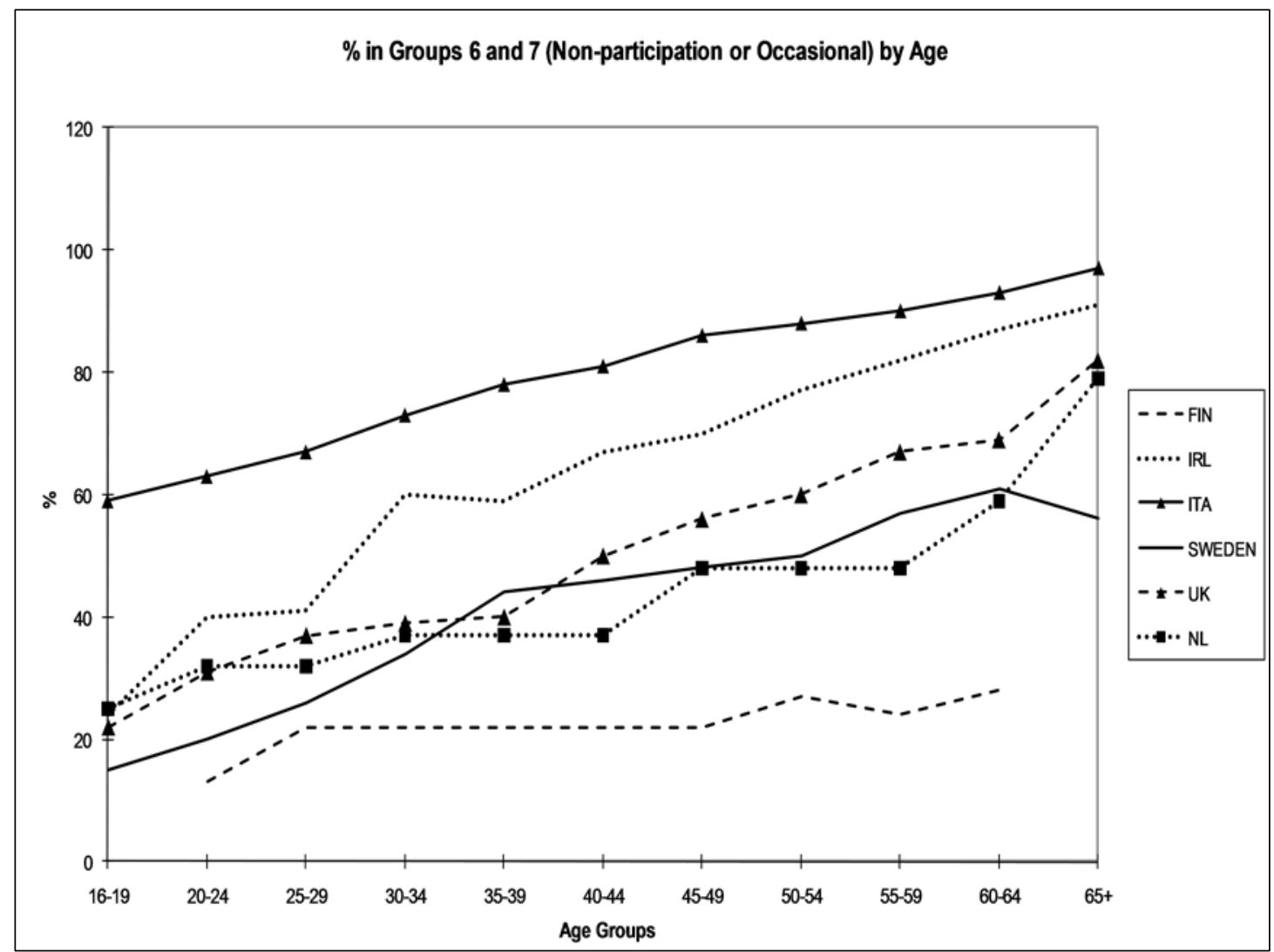

Figure 4: Group 6 and 7 (Non-participation or Occasional) by Age

\section{Developments since the Publication of the COMPASS Report}

Since the COMPASS 1999 report, there has continued to be substantial interest in comparative studies of sports participation in different countries. Cushman, Veal, and Zuzanek (2005) updated their original 1996 study, extending the number of countries from 12 to 15 with the three new countries all being European (Finland, the Netherlands and Russia). Van Bottenburg, Rijnen, and van Sterkenburg (2005) analysed sports participation in 25 European Union member countries. Finland and Sweden emerged again as the European countries with the highest level of sports participation with Denmark not far behind. The north/south divide identified in COMPASS was also evident in this study.

More recently, the European Commission's Eurobarometer survey has been utilised to examine participation in sport in the European Union. This was first commissioned in 2003 and a follow up poll was conducted in 2004. The survey was carried out again in 2009 for the 27 countries that by then made up the European Union. The pattern of participation across Europe in all these Eurobarometer surveys reflects the results of the COMPASS project, with the highest levels of participation in Nordic countries and the lowest in Mediterranean countries, and with similar patterns of association with age and gender.

The most recent contribution in this area is from Nicholson, Hoye, and Houlihan (2011). This study looks at sports participation in 16 countries of which seven (Eng- 
land, the Netherlands, Germany, Norway, Hungary, Bulgaria, Finland) are European. This study has a particular policy orientation in that it is focused on analysing to what extent government policy aimed at increasing sports participation has succeeded. Again, the two Nordic countries in the study, Finland and Norway, emerged with by far the highest levels of sports participation. However, the study concluded that "government policies designed to increase participation have had limited success." It has not been the case that European countries outside of the Nordic countries have been able to increase their participation rates through policy interventions.

In the following two sections we present brief case studies of recent developments in the collection and analysis of European sports participation data and their potential. In addition to developments in research on international comparisons of sports participation there have also been developments in many countries in the way sports participation is now measured: as an example of this we examine the situation in England. When methodological issues regarding cross-national comparison have been resolved, questions of causality of, or influences on, participation levels, arise: in the second section we therefore present an exploratory analysis using the cross-national Eurobarometer data.

\section{Measuring Participation in Sport - the England Experience}

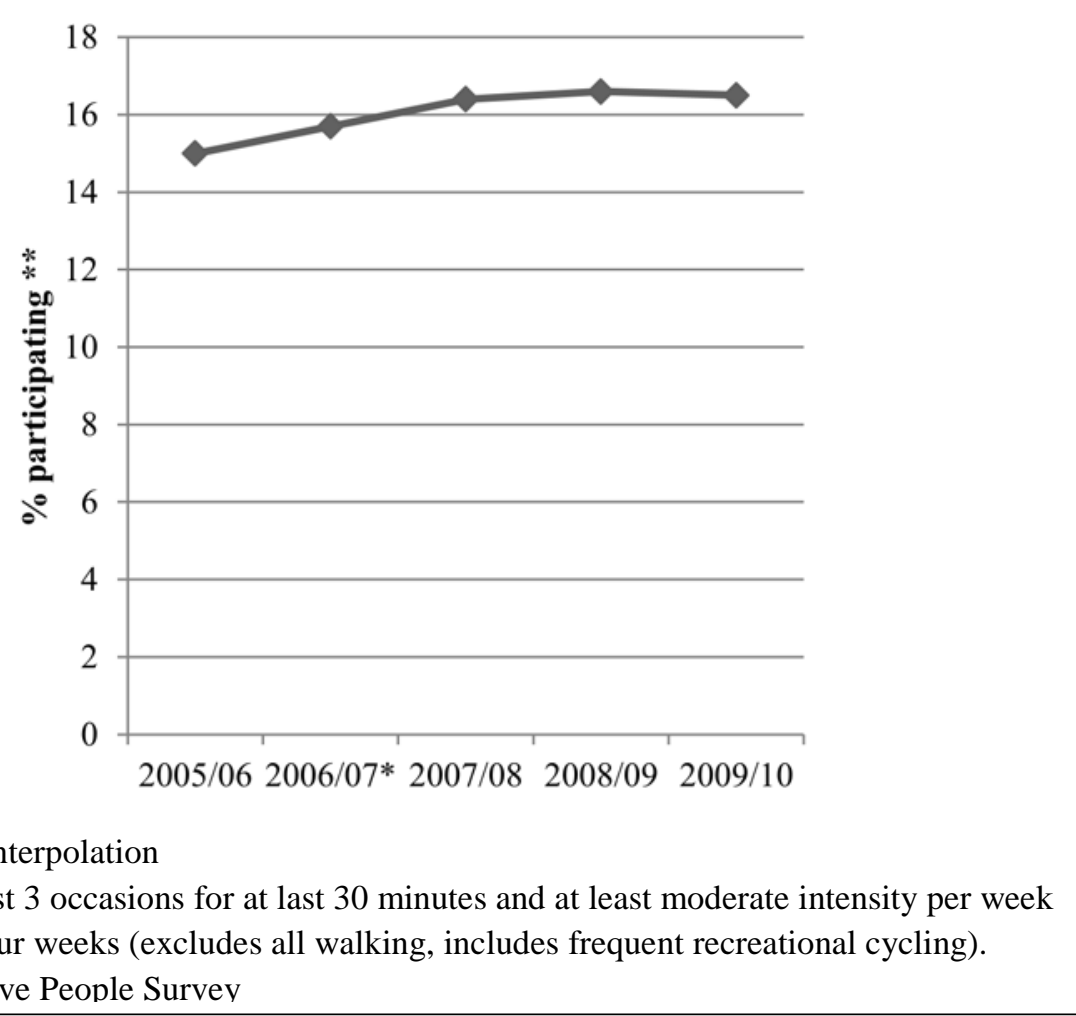

* Authors' interpolation

** On at least 3 occasions for at last 30 minutes and at least moderate intensity per week in the last four weeks (excludes all walking, includes frequent recreational cycling).

Source: Active People Survev

Figure 5: Sports participation in England, 2005-2010 (adults 16+)

Within the European context England offers an interesting case study of how a commitment to invest in much improved measures of participation in sport can take place 
within a policy environment that places a high value on evidence and accountability. Since 2005 Sport England has invested millions of pounds to carry out an annual survey of adult (16 plus) participation in sport. The Active People Survey - the largest survey of its kind in Europe - involves over 188,000 telephone interviews each year (in 2005/6 only the sample size was 363,000 and there was no survey in 2006/7) to establish patterns of sports participation. The survey - which is run continuously throughout the year - includes at its core, measures of the types of sport people take part in, the frequency with which they take part (in a four week reference period), the intensity (in terms of energy expended - light, moderate or vigorous) and the duration (in minutes taking part per session). The survey also includes measures of: the context in which participation takes place (club, competition and coaching/tuition); the levels of volunteering; the reasons why people do or do not take part in sport; and their future intentions. An extensive range of socio-demographic questions is also included, supporting complex social profiling and modelling. (See: Sport England, nd)

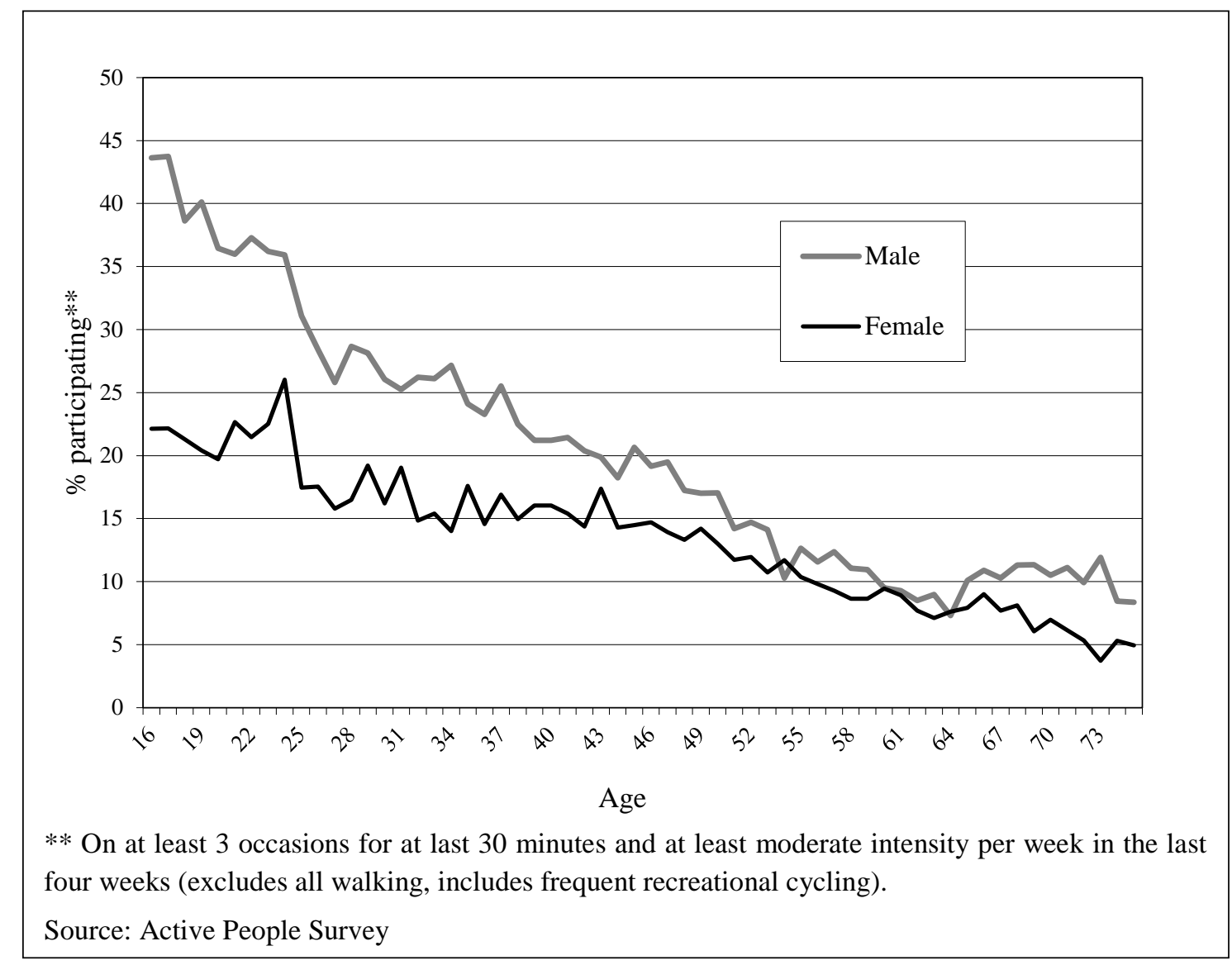

Figure 6: Sports participating by age and gender, England, 2009-10

The Active People Survey has had a transformational effect on policy and practice across the whole of the sport system in terms of: a. strengthening the accountability framework at national and local level: Sport England has a national target to grow and sustain participation rates in sport; national governing bodies have individually negotiated sport-specific targets linked to four year development plans; and many local authorities have adopted sports participation as key service outcome measures; b. in- 
creasing understanding of trends, local geographical variations and determinants of participation; and c. supporting the development of tools that have practical policy and practice applications (such as 'Active People Diagnostic', 'Sport Market Segmentation' and 'Local Sport Profiles' (Rowe, 2009, and see: www.sportengland.org/research /market_segmentation.aspx)).

The survey results in England are consistent with many of the general European trends already outlined in this paper. As Figure 5 indicates, participation rates have increased between 2005/6 and 2009/10 - with most of the increase occurring in the period 2005/6 to 2007/8 and a subsequent levelling of rates in the last two years.

The standard measure of sports participation used in England changed with the Active People Survey. Before this the standard measure of participation was the percentage taking part in sport at least once in the previous four weeks. With Active People, as Figure 5 indicates, the standard measure has changed to the percentage taking part in sport on at least 3 occasions a week for at least 30 minutes and at least moderate intensity in the previous four weeks. This measure excludes all walking (which was included in the old measure) for the same reasons that it was excluded from the COMPASS project. The reason for the change is the increasing emphasis on the health benefits of sport, and health research indicating that the 3 times a week for at least 30 minutes is the minimum required for these health benefits to be realised.

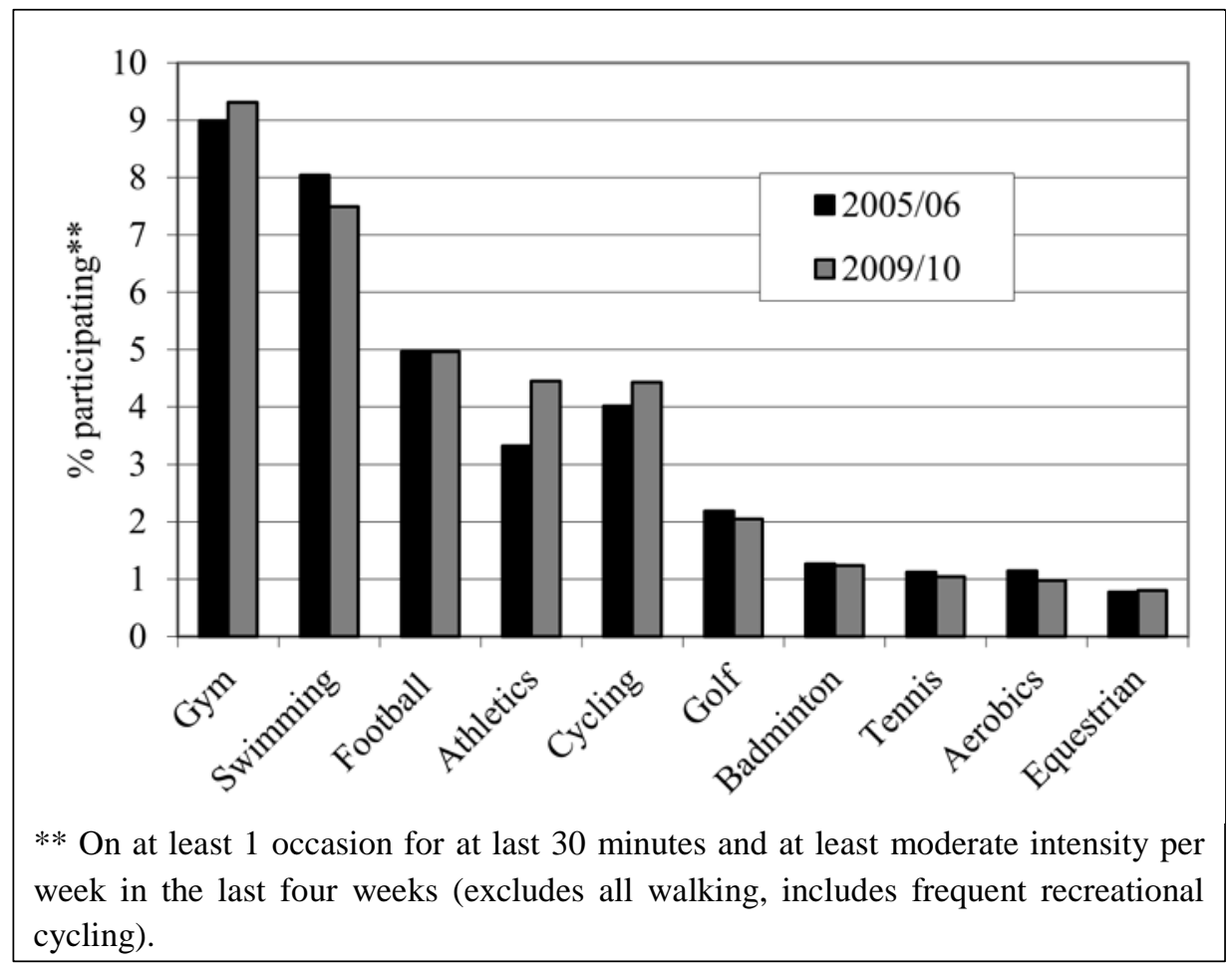

Figure 7: Changes in participation in top 10 sports, 2005-2010, England

England, despite many years of concerted public policy focused on reducing sporting inequities, has yet to overcome the barriers (whether physical, social or psychological) to achieve the greater levels of equality in participation seen in Nordic countries. For example, participation in sport in England declines with age with men having higher 
participation rates than women, particularly amongst young adults, as Figure 6 demonstrates. These 'structural inequities' of age and gender in participation in sport go a long way towards explaining England's 'middle range' European position for overall participation rates as presented in the COMPASS analysis and the more recent Eurobarometer statistics.

The European trend towards more informal participation in health and fitnessrelated sports and a decline in more traditional team sports is replicated in England. As Figure 7 indicates, the biggest growth sports between 2005 and 2010 have been in athletics (which includes road running and jogging), gym and cycling. More traditional sports, such as golf, badminton, tennis, cricket, rugby union and rugby league, have all experienced a decline over the same period.

\section{Influences on Sports participation}

At the individual level, there is a substantial research literature on the factors influencing sports participation, but little exists at the cross-national level. What factors influence different levels of participation in different countries? In particular, which factors are susceptible to policy influence? Exploration of such questions using the COMPASS study and quantitative methods is frustrated in part by the fact that only seven countries were involved and in part by the lack of suitable cross-national data on likely influential factors. Nevertheless, some exploratory, indicative analysis has been undertaken for this paper, both with the COMPASS data and the Eurobarometer data, which offers a larger sample of countries and more recent data. Four variables are explored here, relating to level and distribution of income, time availability and demographics, as summarized in Table 3. A few comments should be made on each of these variables.

- The two COMPASS measures of participation, A and B, relate to the measures used in Figure 2 and 3 above. The two Eurobarometer participation measures, A and $\mathrm{B}$, are defined differently from the COMPASS measures, but they similarly indicate levels of frequency of participation. The 2003 Eurobarometer survey is used because it is closest in time to the inequality measure discussed below. However, the analysis presented here has been replicated with the 2004 and 2009 survey data and the results are broadly consistent (see www.leisuresource.net under 'Other papers'). The 2003 survey covered 15 countries which, with the exception of Luxembourg, coincide with the availability of the inequality measure. The analysis is therefore based on data for: Austria, Belgium, Denmark, Finland, France, Germany, Greece, Ireland, Italy, Netherlands, Portugal, Spain, Sweden and UK.

- GDP per head and paid work time are drawn from the Groningen Growth and Development Centre on-line data-base: 1995 values have been used for COMPASS-related analysis and 2003 values for Eurobarometer-related analysis.

- The 'Aging' variable, indicating the proportion of persons aged 65 and over, is drawn from Eurostat, where the nearest date to the COMPASS surveys is 1999. 
- The final influencing variable relates to income inequality, using data drawn from Wilkinson and Pickett's publication The Spirit Level (2009), which itself draws on World Bank and the Luxemburg Income Study data. The data refer to the year 2000, and earlier for some countries. Wilkinson and Pickett seek to demonstrate that countries with more equal income distributions have better outcomes on a range of social well-being measures, although they do not consider sport. It should be noted that The Spirit Level has been subject to considerable criticism (e.g. Saunders, 2010; Snowdon, 2010) and this is considered further below.

Table 3: Variables used in exploration of causality

\begin{tabular}{|c|c|c|c|c|}
\hline Variable & Definition & Year & $\begin{array}{l}\text { No. of } \\
\text { countries }\end{array}$ & Source \\
\hline \multicolumn{5}{|c|}{ Sports participation } \\
\hline COMPASS & & & & \multirow{3}{*}{ COMPASS (see above) } \\
\hline A & $\begin{array}{l}\text { Intensive, Competitive, and } \\
\text { organised (Group 1) }\end{array}$ & 1995 & 7 & \\
\hline $\mathrm{B}$ & Intensive (Groups 1 + 2) & 1995 & 7 & \\
\hline \multicolumn{5}{|l|}{ Eurobarometer } \\
\hline A & Participation 3+ times/week & 2003 & 14 & \multirow{2}{*}{$\begin{array}{l}\text { Eurobarometer (European } \\
\text { Comm., 2004) }\end{array}$} \\
\hline B & Participation at least once/week & 2003 & 14 & \\
\hline \multicolumn{5}{|c|}{ Influencing factors } \\
\hline GDP/head & $\begin{array}{l}\text { Gross Domestic Product per person } \\
\text { in \$US }\end{array}$ & $\begin{array}{c}1995 \& \\
2003\end{array}$ & 14 & \multirow{2}{*}{$\begin{array}{l}\text { Groningen data-base (Gro- } \\
\text { ningen Growth and Devel- } \\
\text { opment Centre, 2010) }\end{array}$} \\
\hline Paid work time & $\begin{array}{l}\text { Annual average paid working hours } \\
\text { by employed persons }\end{array}$ & $\begin{array}{c}1995 \& \\
2003\end{array}$ & 14 & \\
\hline Aging & $\%$ of population aged $65+$ & $\begin{array}{c}1999 \& \\
2003\end{array}$ & 14 & $\begin{array}{l}\text { Eurostat } \\
\text { (European Comm., 2010) }\end{array}$ \\
\hline Inequality & $\begin{array}{l}\text { Ratio of top 20\% to bottom } 20 \% \\
\text { share of income }\end{array}$ & c. 2000 & 14 & $\begin{array}{l}\text { Spirit Level } \\
\text { Wilkinson \& Pickett, 2009) }\end{array}$ \\
\hline
\end{tabular}

A summary of the analysis is presented in Table 4. Relationships between individual participation measures and individual influencing variables are examined using correlation coefficients. Due to the small sample size for the COMPASS data, only correlation coefficients above 0.83 are statistically significant (at the 95 per cent level) and this applies to none of the coefficients, although relationships with inequality, particularly participation measure B, are close. The size and negative sign of the coefficients for inequality suggests the possibility that societies with more unequal income distributions have less sports participation.

In the case of the Eurobarometer data, with a sample of 14 countries, coefficients above 0.46 are significant at the 95 per cent level. The relationship between sports participation and inequality is confirmed, in this case at a statistically significant level, and GDP per head is shown to be significant for participation measure B. Working hours and aging of the population are shown to have negative but statistically insignificant, relationships with participation. Multiple regression analysis, involving all four variables, results in values of $\mathrm{R} 2$ of between 0.38 and 0.70 . This is an improvement on the single variable analyses (since a $\mathrm{R} 2$ values of 0.38 and 0.70 are mathematically equivalent to $\mathrm{R}$ values of 0.62 and 0.84 respectively). 
The earlier discussion of the COMPASS data suggests a three-way division between Nordic countries, the middle band and Mediterranean countries. Table 4 shows that these three groups have distinctive characteristics. In particular, the Nordic group have the highest sports participation rates and lowest levels of inequality, while the Mediterranean group has the lowest sports participation rates and highest levels of inequality. For the other variables, the Mediterranean group has the lowest per capita income, the longest working hours and the largest proportion of people aged 65 and over, but the other two groups are similar to each other.

Table 4: Relationships between sports participation and influencing variables, 2003

\begin{tabular}{lccccc}
\hline $\begin{array}{l}\text { Sports participation } \\
\text { data } \\
\text { (no. of countries) }\end{array}$ & $\begin{array}{c}\text { GDP per } \\
\text { head }\end{array}$ & $\begin{array}{c}\text { Paid work } \\
\text { hours }\end{array}$ & Aging & Inequality & All four variables \\
\hline COMPASS (7) & \multicolumn{5}{c}{ Correlation coefficients } \\
\hline A & 0.06 & -0.15 & -0.09 & -0.78 & R squared \\
\hline B & 0.09 & -0.20 & -0.10 & -0.82 & \\
\hline Eurobarometer (14) & \multicolumn{5}{c}{ Correlation coefficients } \\
\hline A & 0.36 & -0.15 & -0.24 & $-0.57^{*}$ & $0.38^{*}$ \\
\hline B & $0.52^{*}$ & -0.34 & -0.35 & $-0.65^{*}$ & $0.70^{*}$ \\
\hline
\end{tabular}

*=significant at the $95 \%$ probability level. Data sources; see Table 3

This finding can be related to some of the criticism of The Spirit Level which has suggested that the relationships between inequality and the various social well-being measures used by Wilkinson and Pickett are invalid because they are heavily influenced by one or two extreme 'outliers', such as the USA and Portugal, which have high levels of inequality, and the Nordic countries with low levels of inequality. This is true of the current analysis. Figure 8 shows that, Portugal, Finland and Sweden are outliers. When these are excluded from the analysis, the remaining eleven countries show no relationship between sports participation and inequality. However, when the three groupings of countries are indicated (by the different shaped markers in Figure 8), the so-called 'outliers' can be seen as members of two of the three distinctive groups.

Regarding policy implications of these findings: all governments aim to increase GDP and there is some evidence to suggest that this is associated with increased sports participation, although this may be the case only up to a certain level. Similar relationships, although not statistically significant, can be observed in the case of paid working hours and the aging of the population, although the latter is an area of policy concern rather than a policy measure. The relationship between the inequality variable and sports participation shows the strongest and most consistent statistical significance. Possible explanations for the strength of this relationship could be that more equal countries generally have higher levels of progressive taxation and associated public expenditure and this could include expenditure on sport facilities and programmes. They may also be more politically open to generous labour conditions, particularly in relation to working hours and holidays. It is also possible that, within the sport sector, more emphasis is given to grass roots participation as opposed to elite performance. 
Other factors, such as history, culture and environmental conditions are, of course, also involved. Exploration of these possibilities clearly merits further research.

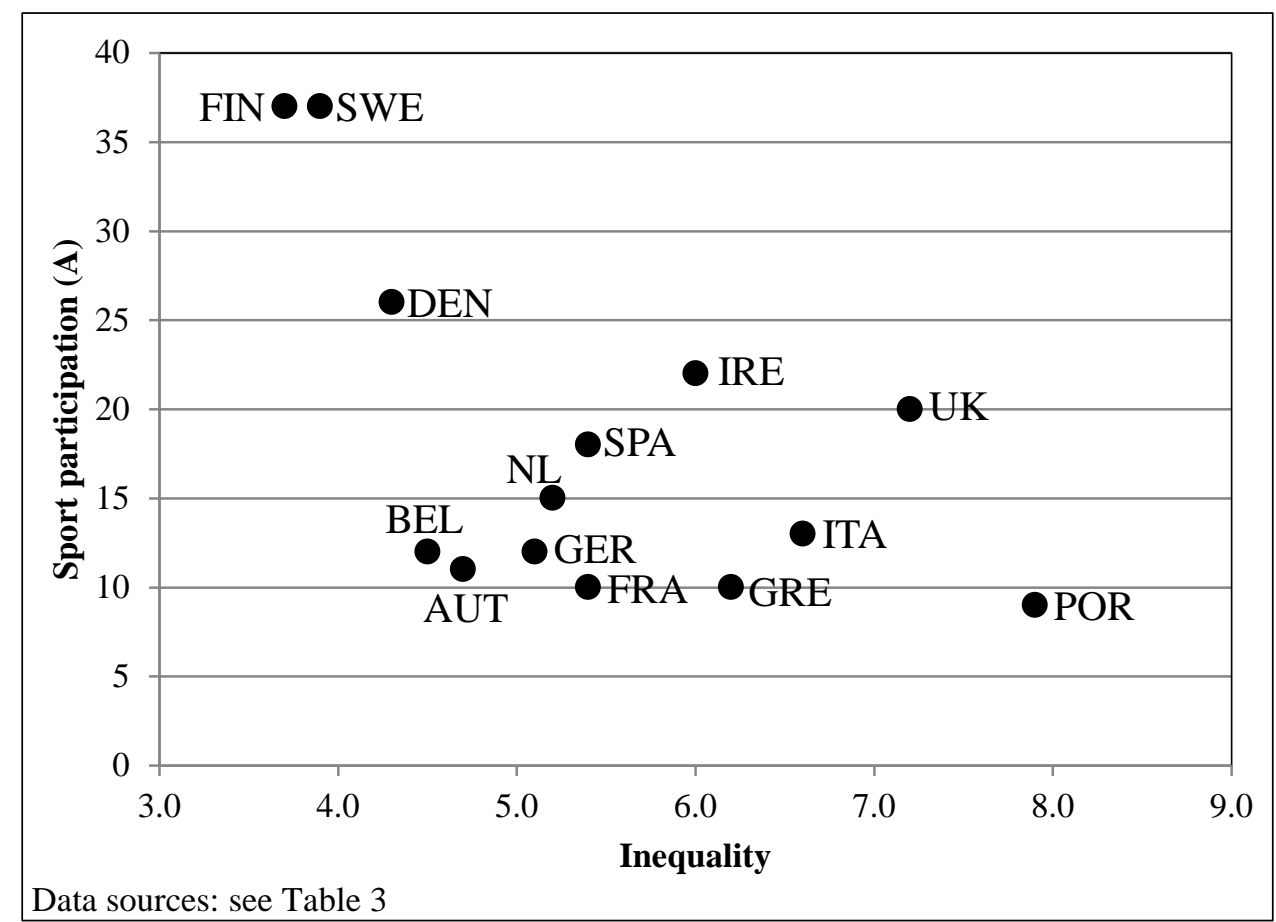

Figure 8: Relationship between sports participation and inequality

\section{Conclusions}

The more recent studies referred to above have tended to reinforce the results of COMPASS rather than significantly change them. It is clear that Nordic countries have substantially higher participation rates in sport than other European countries. These countries also are the only countries in Europe that also have the same number of women participants as men. The question arises as to whether there is a need for a new COMPASS project. The answer is probably yes, since the policy agenda around sport has moved on in that the health benefits of sport have come much more to the fore in recent years. Because of this the way in which we measure sports participation has also moved on.

Of the seven groups identified in the COMPASS framework, only the first two have participation intensity of more than twice a week. The third group has a minimum intensity of just over once a week. In England at the moment, the main indicator of sports participation used by policy bodies has changed from "at least once in the last four weeks" at the time of the COMPASS project to "at least 3 times a week for a duration of at least thirty minutes" now. This change has come about because health research has indicated that this is the minimum intensity of sport activity that will significantly contribute to health status.

Sports participation in any country follows a distribution from those participating very often to those participating occasionally. The 'regular' participants in the COMPASS project were at the middle of this distribution with participation intensity be- 
tween once a month and once a week. In any new COMPASS project it would now be necessary to change the definition of 'regular' to a higher level of intensity, in other words to concentrate on those participants on the more frequent side of the distribution, with less attention being given to the 'irregular' and 'occasional' groups of the old COMPASS framework.

The COMPASS project did show that it was possible to make meaningful international comparisons of sports participation despite the well documented difficulties in doing this. The sports participation patterns established by COMPASS have been confirmed in research carried out in the last decade. But none of that research has followed the approach taken by COMPASS. Perhaps there is a need for a new COMPASS study but such a study would need to adapt the analytical framework to take account of the new policy emphasis on the more intensive measure of participation.

\section{References}

Council of Europe (1992) European Sport Charter (revised 2001). Strasbourg: Council of Europe, available at: www.coe.int/t/dg4/sport/commitments/Default_en.asp.

Cushman, G., Veal, A. J. \& Zuzanek, J. (Eds), (1996). World Leisure Participation: Free Time in the Global Village. Wallingford, UK: CAB International.

Cushman, G., Veal, A. J. \& Zuzanek, J. (Eds), (2005). Free Time and Leisure Participation: International Perspectives, Wallingford, UK, CABI Publishing.

European Commission (2004). The Citizens of the European Union and Sport: Special Eurobarometer 213. Brussels: European Commission, (contains 2003 and 2004 survey results) available at: http://ec.europa.eu/public_opinion/archives/ebs/ebs_213_report_ en.pdf.

European Commission (2010). Eurostat: Population, Brussels: European Commission, available at: http://epp.eurostat.ec.europa.eu/portal/page/portal/population/data/ main_tables.

Groningen Growth \& Development Centre (2010). Conference Board Total Economy Database, January 2010, Groningen, University of Groningen, available at: www. conference-board.org/data/economydatabase/.

Kamphorst, T. J. \& Roberts, K. (1989). Trends in Sport: A Multinational Perspective. Voorhuizen, Netherlands: Giordana Bruno Culemberg.

Nicholson, M., Hoye, R. \& Houlihan, B. (2011). Participation in Sport: International Policy Perspectives. London: Routledge.

Rodgers, B. (1977). Rationalising Sports Policies: Sport in its Social Context: International Comparisons. Strasbourg: Council of Europe.

Rowe, N. F. (2009). The Active People Survey: a catalyst for transforming evidence-based sport policy in England. International Journal of Sport Policy, 1 (1), 89-98.

Saunders, P. (2010). Beware False Prophets: Equality, the Good Society and The Spirit Level. London: Policy Exchange (available at: www.policyexchange.org.uk).

Snowdon, C. (2010). The Spirit Level Delusion: Fact-checking the Left's New Theory of Everything. Ripon, N. Yorks: Little Dice (www.spiritleveldelusion.com).

Sport England (nd). Active People Survey, London: Sport England, available at: www.sportengland.org/research/active_people_survey.aspx. 
UK Sport, Sport England and CONI (1999). Sport Participation in Europe: COMPASS 1999. London: UK Sport.

Van Bottenburg, M., Rijnen, B. \& van Sterkenburg, J. (2005). Sports participation in the European Union: Trends and Differences. Nieuwegein, Netherlands: W. J. H. Mulier Institute/Arko Sports Media (www.arko.nl/index.php).

Wilkinson, R. \& Pickett, K. (2009). The Spirit Level: Why More Equal Societies Almost Always do Better. London: Allen Lane.

Chris Gratton is Professor of Sports Economics and Director of the Sport Industry Research Centre (SIRC) at Sheffield Hallam University, UK. His main areas of research include: the economic benefits of major sports events; measuring the economic importance of sport including the use of satellite accounts for sport; and the analysis and modelling of large sports participation surveys. He has represented the UK on the EU Workshop on Sport and Economics since 2006.

Sport Industry Research Centre, Sheffield Hallam University, Collegiate Campus, Sheffield, S10 2BP, UK

E-mail: c.gratton@shu.ac.uk

Nick Rowe is Head of Strategy, Research and Planning for Sport England, the leading national sports development agency in England. His specialist area is in 'sport and social policy' research. He has been responsible for managing many large research studies including the Allied Dunbar National Fitness Survey and the three National Surveys of Young People and Sport in England. He is currently Project Director for the Active People Survey - the largest sports participation survey in Europe.

Strategic Lead for Research and Evaluation, Sport England, 3rd Floor, Victoria House, Bloomsbury Square, London, WC1B 4SE, UK

E-mail: nick.rowe@sportengland.org

A. J. Veal is Adjunct Professor in the School of Leisure, Sport and Tourism in the University of Technology, Sydney, Australia, and worked previously in the universities of Birmingham and North London. He is past president of the Australian and New Zealand Association for Leisure Studies (ANZALS) and of the UK Leisure Studies Association.

School of Leisure, Sport and Tourism, University of Technology Sydney, UTS Business School, PO Box 222, Lindfield 2070, Australia

E-mail: Tony.Veal@uts.edu.au 